\title{
The Impacts of Power Market Reform on Power Grid Planning and
}

\section{Strategy Analysis}

\section{Hong Dong ${ }^{1, a}$, Dunnan Liu ${ }^{2, b}$, Guanxiong Ma ${ }^{1, c}$ Guangyu Qin ${ }^{2, d}$ Mingguang $\operatorname{Liu}^{2, e}$}

${ }^{1}$ Guangzhou Power Supply Co., Ltd. Zhengzhou 450052, China

${ }^{2}$ North China Electric Power University, Changping District, Beijing 102206, China

adongh@guangzhou.csg.cn, bliudunnan@163.com, ${ }^{\mathrm{c} \text { magx@guangzhou.csg.cn }}$

d13263462372@163.com, ${ }^{\mathrm{e}}$ 1718241359@qq.com,

\begin{abstract}
Keywords: power market reform, grid planning, impact analysis, reventive solution
\end{abstract}
Abstract. Along with the economic and social development in our country, the demand for electricity and energy by society has been constantly increasing. The new round of market-oriented electricity reform launched in 2015 clearly defined the reform path of "three liberalization, three strengthening and one independence". One of the significant measures is to strengthen the overall planning of electric power. However, with the power market entering the deep end, the liberalization of the electricity distribution market, the independence of transmission and distribution prices, changes in market mechanisms and environmental changes such as the diversification of the market entities, all brought about an impact on the planning of power grid enterprises. Based on the requirements of market construction, the paper divides the three stages of the market reform process and clarifies the main market characteristics and key points of each stage. From the perspective of the role and positioning of power grid planning, goals and thinking This paper analyzes the impact of electricity market reform on power grid planning. Based on these factors, this paper analyzes the impact of power market reform on power grid planning from the perspectives of principles, effectiveness, work flow, investment control and investment arrangement. Four aspects of cooperation to develop coping strategies, with a view to market participants and policy makers to provide a reference.

\section{Introduction}

With the economic and social development in our country and the continuous deepening of power reform, the operation of power plants and power grids in our country will be completely separated, and then the power generation companies and power grid companies will be independent. At the same time, from the current development situation, the power grid will have a natural monopoly in the future development process and will be able to exert its own role and obtain better benefits in the course of its development.

In a large number of references, Literature ${ }^{[1]}$ made a detailed analysis of the power market reform program and pointed out that the power market reform will play a significant role in promoting the improvement of China's market economy system and the development of the power industry. The literature ${ }^{[2]}$ put forward to improve the supervision and management of transmission and distribution tariffs and monitoring methods to achieve supervision of transmission and distribution tariffs scientific, standardized and institutionalized to promote electricity 
market-oriented reforms; literature ${ }^{[3]}$ put forward in the power market reform supporting documents Distribution price reform, electricity market construction, sales side let go and other core points of view. Reference ${ }^{[4]}$ reviews three major phases of China's power reform and introduces China's power-related reform measures. It also points out that the use of renewable energy for power generation can reduce pollution. In the development of power industry, power grid planning is the basic work. Power grid planning is directly related to the overall efficiency of the use of electricity and energy. The above literature does not address the importance of grid planning in the power industry. In the process of carrying out research work, this paper mainly studies the impact of the power market reform on the power grid planning, and puts forward feasible suggestions and strategies for the power grid planning of these power companies.

\section{The Overall Process of China Power Market Reform}

According to the requirements of China's electricity market reform, the overall progress of China's electricity market reform is divided into initial pilot phase, phase of promotion and phase of market improvement. The three stages closely linked to continuous deepening. With the advancement of the reform process, government functions, electricity tariff reform and market construction have been gradually perfected. Development plans for power generation have been gradually liberalized and the development of clean energy and distributed generation has progressed in an orderly manner.

Start the pilot phase. In the pilot phase of the reform of the power market, the key tasks are to launch pilot projects to liberalize the power supply side, gradually liberalize the power generation and sales prices, steadily push forward the reform of transmission and distribution tariffs, and initially establish provincial power plants that trade large power users and power generation enterprises Trading platform, the establishment of cross-provincial long-term bilateral transactions and short-term bidding trading of national power trading platform.

In terms of government functions, the administration will improve the unified plan for the development of electric power, change the way of approving investment in electric power projects, and conduct pilot projects of bidding and tendering for power supply projects. Perfecting the power industry regulatory legal system, making major user direct trading pilot and sales of electricity market pilot program, the development of regional power market access rules and trading rules, strengthen the market competition order supervision. Strengthen the supervision over the cost, income, safety and service of the grid according to law.

In deepening bilateral pilot projects in the electricity market, the provincial electricity trading platform was established, large users and power generation enterprises were organized to conduct free consultations or centralized bidding transactions. In the pilot launch of the electricity sales market, the rules for access to electricity sales business were formulated to allow social capital And private-owned enterprises to set up power sales enterprises and encourage enterprises engaged in contractual energy management and energy-saving services to engage in power-selling businesses. In promoting the construction of regional power markets, the government set up the State Power Trading Platform,realize the market-based transatlantic power trade, Standardization and contractualization. Establish provincial power trading platform, organize large users, power selling enterprises and power generation enterprises meeting the access requirements and conduct transactions through independent negotiation and centralized competition.

Gradual promotion phase. The key tasks of the phase of promotion are as follows: on the basis of summing up the pilots and in accordance with the principle of local conditions, push forward user choice and power supply side competition in most areas of the country, deepen regional 
electricity market construction, promote electricity price mechanism and perfect laws and regulations, Establish a new universal service mechanism.

Gradually release large and medium users to choose, allowing qualified users to choose for their power supply business, allowing eligible companies to engage in business of purchase and sale of electricity, the formation of diversified power sales competition in the main pattern; and gradually improve the regional electricity market, which To realize the mutual openness and integration of the transaction between the State Power Trading Platform and the trade transactions organized by the provincial trading platforms and to conduct transactions through independent negotiation and centralized competition, and gradually increase the trading volume and trading varieties.

To establish a market pricing mechanism for power generation links and sales link prices, including three mechanisms: establishing a bidding mechanism for power generation bidding, establishing a government pricing mechanism for grid links and establishing a market competition mechanism for sales links. Establish a unified national grid management system to achieve a fair and open power grid.

Improve the electricity laws and regulations and the electricity regulatory mechanism, perfect the electricity regulatory measures and supervision methods, strengthen the price in the power generation sector, strengthen the cost supervision in the electricity sector, and strengthen the supervision of service quality in the power supply sector. Establish the universal electricity service mechanism and clarify the responsibilities of universal service The main body and the implementation of the main sources of financial stability, improve service targets, standards and so on.

Full process stage. The key tasks of the overall process are as follows: the electricity market is gradually maturing, the electricity development is entering a mature stage, the pricing mechanism, the laws and regulations system, the long-term mechanism for the sustainable development of agricultural power, the universal service mechanism and other market supporting mechanisms are mature and perfected.

With the maturity of basic conditions such as grid structure, technical support system and management capability, the functions of national power trading platform and inter-provincial electricity trading platform are fully integrated to form a unified and open and orderly competitive regional electricity market system; the goal of improving government management efficiency , Optimize the government management of the power industry, management tools and management content, improve the scientific and efficient government regulatory mechanisms.

\section{Impact of Power Market Reform on Power Grid Planning}

The impact of power system reform on power grid enterprises is multifaceted. From the regulatory perspective, under the cost-plus pricing approach, grid companies have potential motivations for overinvestment, so grid investment will be subject to more stringent government regulation in the future, and investment in grid companies will also be weaker, but the transition is still underway period. At the same time, the current valid asset verification process, the operating rules are not clear, the boundary conditions are not clear, there is a big risk; strong revenue and cost control will also affect the power company's cash flow, and investment in capital investment required more funds Large, may increase some financial costs. In addition, in the distribution network planning and investment, the orderly release of the business of placing electricity to social capital and the gradual release of incremental power distribution investment business to eligible market entities will diversify the main components of the distribution network planning and construction, Thus increasing the difficulty of unified planning and orderly construction of distribution network. 
Specific to the planning and investment aspects, the impact is reflected in the following aspects.

Impact on grid planning role and positioning. Clear power grid planning in the role of the grid, so as to adjust and optimize the planning objectives: First, to reflect the attributes of public utilities, play a "supply and demand" of the bridge role. One of the purposes of the power system reform is to introduce market mechanisms in some areas to break the original market structure and to change the positioning of power grid enterprises. The second is to play a guiding role, highlighting the overall situation. Electricity system reform has opened up the market for placing electricity and selling electricity. Diversified entities are likely to cause the market to be uncoordinated and inconsistent, posing a hidden danger to the system planning and operation. Third, it is necessary to give play to the coordinating role and integrate the needs of multiple subjects so that the planning programs and projects can "fall to the ground, land well, and effectively land."

Impact on the goal and mentality of power grid planning. In order to ensure the safe and stable operation of the system and to ensure the basic needs of the economy and society for electric energy, the objectives of the traditional power grid planning mainly include: (1) Reasonable structure: ensuring space for improvement, adjustment and expansion of the power grid; (2) Reliable power supply: Robustness to meet the "N-1" criteria; (3) adaptability: the grid structure should have the ability to adapt to the foreseeable risks.

With the marketization of electricity reform, new requirements have been put forward for the traditional grid planning. The impact of the power market reform on the grid planning objectives include: (1) stressing risk management and control awareness and strengthening flexible and reliable targets; (2) emphasizing service awareness, And strengthen the social welfare goals; (3) emphasize the overall situation and coordination awareness, and strengthen the systematic goals.

Impact on grid planning principles. The new environment formed after the reform of power system has brought a certain impact on the goal of power grid planning and the corresponding planning principles will also be adjusted. Mainly in: (1) planning programs should reflect the quality of service, green low-carbon principle. The power system reform document clearly defined the positioning and attributes of power grid enterprises, emphasizing the important status of renewable energy sources; (2) the principle of planning has been transformed from safety and reliability to flexibility and reliability. The new electric power reform policy under the power grid planning, we must fully consider the distributed energy on the distribution network brings the complexity and uncertainty, through comprehensive and meticulous planning, the grid has more flexibility;(3) The power grid in the future involves many areas and various forms of cooperation. They need to be open-minded and reflect the principle of shared integration. The power grid under the new reformation of electric power system, the government encourages the participation of private capital, and grid companies compete with the grid involved in the planning and construction.

Impact on the Efficiency of Power Grid Planning. On the one hand, the reform of transmission and distribution tariffs and the liberalization of the market for placing electricity will, to a certain extent, stimulate the grid companies to plan ahead of time and invest in advance to seize the market. On the other hand, the policy of electric power reform on the positioning and regulation of power grid enterprises requires that they must invest rationally, Effective investment, planning safety standards will also control its over-investment and unnecessary investment. Therefore, the reform of the power system requires that the investment planning of power grid enterprises must take a lean approach. From the perspectives of planning objectives and principles, coordination of planning plans, investment scale and structural optimization, and comprehensive risk assessment, it is necessary to ensure that planning projects are recognized by regulatory authorities and to ensure the effective landing of the planning project. 
Impact on Grid Planning Workflow. Grid planning is a basic work that is directly related to the overall efficiency of the use of electricity and energy and plays a decisive role in the development of a region and even of our entire country. The traditional power grid planning process mainly includes the following steps: (1) predict the future power planning and load trend; (2) predict the future electricity market conditions and electricity prices; (3) analysis and screening of various planning programs; (4) ) propose the alternative planning plan; (5) estimate the possible return; (6) risk assessment and investment analysis.

A feasible grid planning solution must be able to meet future grid market requirements for grid capacity "to ensure the reliability of grid operation" and to safely recover investment costs. Therefore, the power grid planning in the new situation needs a comprehensive analysis of the power system from an economic point of view and an engineering point of view, and finally obtains the market expected value of the power demand of the transmission network. Therefore, in the use of traditional load forecasting program, we must increase the consideration of various uncertain market factors in the future.

\section{Strategy of Power Network Planning under Market Reform}

\section{Improve the planning methods.}

- Uncertainty planning approach. With the implementation of the new electric power reform, it is no longer suitable to consider the power demand of the demand side with a single consideration. The development of distributed generation needs to be dealt with by the method of uncertainty. In the face of the randomness of distributed power generation, many literatures adopt the method of chance constrained programming to deal with. Scenario analysis planning is also an uncertain planning model. This method has good effect on power system simulation with random variables.

- Improve the planning process. In the market environment, due to the relative independence of the transmission and transportation links and the large-scale integration of new energy sources, the double-sided randomness of the power system is strengthened. Therefore, the grid congestion problem must be paid attention to in the planning stage. One of the goals of grid planning in the new situation is to reduce existing or future grid congestion. Because the marginal node price can reflect the grid congestion to a certain extent, we can obtain the planning plan that the grid needs strengthening by calculating the marginal price difference between the nodes

- Diversified load forecasting methods. Power load forecasting is the basis of distribution network planning, and accurate forecasting has a decisive influence on the quality of distribution network planning. Different types of loads are required for different types of loads: Traditional loads are estimated by using parameter estimation and artificial intelligence. With the implementation of the new plan, energy saving and emission reduction requirements will be higher and higher. The proportion of new loads such as electric vehicles will gradually increase. It is necessary to fully study the new load characteristics such as electric vehicles. On the basis of this, the load forecast is made by predicting the number of electric vehicles in the area.

- Planning to consider uncertainty. The new electricity reform policy mentioned the incremental distribution business to let go and encourage private capital to participate in the distribution network construction. The increase of implementers and planners of the distribution network brings uncertainty to the final implementation of the plan. At the same time, we should conduct a risk assessment on the distribution network planning project to 
deal with possible uncertainties.

\section{Planning ideas adjustment.}

- Give full play to professional advantages, guide the power grid planning and decision-making. In the new market environment, power grid companies should give full play to their professional and technical advantages, and combine the relevant government requirements and standards with professional proofs in the planning process and guide the government in making scientific decisions on power grid planning.

- Pay attention to the solution of existing problems and promote the balanced development of power grid. Guided by the new policies, the primary goal of grid development is to meet the normal power supply needs of users.

- Refine planning project classification to promote effective investment in power grid. In the process of planning, we should take the initiative to adapt to the requirements of electricity price reform and external regulation, and reasonably determine the appropriate scale of investment and the investment of new assets in various professions.

- Optimize the ranking of planning projects and keep the dynamic maintenance of storage projects. According to the various types of power grid planning priorities, divided into different categories and different stages of the planning project library. For the annual rolling plan and five-year plan, it is necessary to conduct an in-depth study on the necessity and achievement of the project one by one, attach importance to the establishment of the planning project library and strictly control the project storage.

\section{Asset Efficiency Guide.}

- Make basic data verification, find out the bottom line. The basic data verification is done, including the verification of the existing assets of the power grid, the verification of the important operation data of the existing power grid and the verification of the important parameters of the operating cost of the grid company. Finding the bottom line of grid assets, through the vigorous development of grid assets inventory, distinguish ownership of assets; accurate accounting of the sub-points of the voltage level and the original value of fixed assets.

- Strengthen guidance to improve grid efficiency and asset efficiency. After the implementation of the electric reform policy, the economic benefits of grid construction and the efficiency of the utilization of grid assets will surely be supervised by the government. All these put forward higher requirements on the planning, development, asset management and investment control of grid companies.

Through the guidance of power grid planning and reasonable layout of sites and network wiring, the power utilization ratio of power transmission and transformation equipment should be operated in a reasonable range. The requirements of planning research should be increased, the implementation effect and benefit evaluation of individual projects should be emphasized, and the overall system should be emphasized that solve the existing problems of the power grid and improve the comprehensive benefits of power grid planning and construction.

\section{To communicate and collaborate with the government.}

- Change the working concept, take the initiative to cooperate. The power grid company should change its original concept of planning independent decision-making work and take the government's position and attitude into account in the decision-making process. At the same time, the power grid company should take the initiative to strengthen communication and coordination with relevant government departments throughout the whole process of 
power grid planning.

- Participate in formulating government plans and achieve common goals. Power grid companies should actively and deeply participate in the drafting and revision of the government's transmission and distribution price reform program, give full play to their professional advantages, guide the formulation of relevant government programs, make reasonable demands and suggestions on related research, and strive to work with the government in grid construction goals and planning technologies Principles and regulatory standards for assessment and other aspects of agreement to ensure the sustainable development of the company and ultimately achieve the common goal of serving the social and economic development in the region.

- Fully express their demands and strive for favorable support. Grid companies have professional advantages. Under the supervision of the government, grid companies should make full use of their professional advantages and make clear suggestions during the formulation of planning principles and work progress, and through various types of technical discussions or the use of various types of opportunities for foreign exchange, Express demands, for the government and relevant units to understand and support, guide the government's scientific supervision.

\section{Conclusion}

The paper analysis and research about the overall process of three stages of china power market reform .at the start of the pilot phase,the key task is to transform government functions, the safe implementation of electricity price reform, deepen direct trading trial between large users and power enterprises.launch trials to open the market for selling electricity.promote regional electric power market ; In the promotion stage, the key task is to gradually open option of large and medium users ,foster the subject of multiple sell electricity, the regional electricity market is gradually improved,and improve the mechanism of electricity price, achieve grid fair open, perfect the laws and regulations system and electric power supervision mechanism, establishing the power universal service mechanism; The key task of the comprehensive construction phase is to form a unified ,open and competitive regional electricity market system and improve the scientific and efficient government supervision mechanism. Therefore, the reform of power market puts forward new requirements for grid planning. In the new development environment, the grid planning can not achieve very good results, so it will affect the normal operation of the power grid and cannot meet the needs of the society for power energy. The influence of electric power system reform of power grid planning is all-round, mainly reflected in the role and positioning, target and way of thinking, principle and planning depth, effectiveness and working process, the overall power grid investment control, etc. Under the background of electric power market reform, power grid planning strategy should consider the following aspects :the advance of planing method,the adjustment of planning ideas, the guidance of efficiency of assets, the cooperation with the government. At the same time, the grid enterprises should take a large amount of uncertainties in the process of grid planning, so that they can play their own role better.

The electricity market reform will have a direct impact on the power grid company's power grid planning. The development process of power grid enterprises in the future, will become a strong independent and specific power market participants. During its development, it will be supervised by corresponding national intelligence agencies to ensure that grid companies can provide fair, just and open transmission services to both supply and demand parties in the market. Therefore, the development of the power grid needs more sophisticated power grid planning. Only in this way can 
we better play our role. Therefore, it is of great value and significance to study the impact of power market reform on power grid planning and its countermeasures. In this paper, the direction of the electric reform and the power grid enterprise adaptive operation mode research and electric power development under the situation of power grid development, the key technology direction is not discussed in two aspects, further research is needed.

\section{References}

[1] Shi Lu. A new round of power system reform program interpretation [J]. Technology Innovation Herald, 2016,13 (34): 225-226 + 228.

[2] Liu Bin.Analysis on the Impact of Electric Power System Reform on Power Grid Enterprises [J]. China Electric Power (Technology), 2014, (11): 160-163.

[3] Shen Fang, Song Zoran, Zhang Mingli, Liu Yang, Wang Ye.Power system reform progress and existing problems [J]. Northeast Electric Power Technology, 2017,38 (05): 1-5.

[4] Jian Jiao,Xian Jia Wang. Electricity Market Reforms and Sustainable Development in China[J]. Advanced Materials Research,2012,1566(433):.

[5] Yan Dengfeng. Deepening China's power system reform study [D]. Southwestern University of Finance and Economics, 2012.

[6] Zhu Zhongli, Jia Xuan, Xu Q. Impact of electricity market reform on grid planning [J] .China Hi-tech Enterprise, 2015, (19): 38-39.

[7] Chen Fen. Some Reflections on the Current Reform of China's Electricity Market [J]. Manager, 2014, (36): 225-226.

[8] Wang Danli.Analysis of the Impact of Electricity Market Reform on Power Grid Planning [J]. Technology and Market, 2017,24 (04): 327-329.

[9] Gai Qiqing. The impact of electricity market reform on power planning [D].Shandong University, 2005.

[10] Liu Bin. On the impact of power system reform on power grid enterprises [J]. China Electric Power (Technical), 2014, (11): 160-163.

[11] Zhang Zixiao.Effects of power system reform on grid enterprises [J]. Enterprise Reform and Management, 2016, (08): 192.

[12] Feng Yongsheng. Understanding China's Electric Power System Reform: Market-oriented and Institutional Background [J] .Report of Thinker, 2016,1 (05): 22-50 + 141-142.

[13] Wang Jingwei. China power system reform theory and problems [D]. Capital University of Economics and Business, 2008.

[14] Li Xing. China Southern Power Grid strategic direction and countermeasures under the background of electric power system reform [D]. Southwest Jiaotong University, 2017.

[15] Shi Lu. A new round of power system reform program interpretation [J]. Technology Innovation Herald, 2016,13 (34): 225-226 + 228.

[16] Ming Meng,Sarah Mander,Xiaoli Zhao,Dongxiao Niu. Have market-oriented reforms improved the electricity generation efficiency of China's thermal power industry? An empirical analysis[J]. Energy,2016,: 